\title{
Is the LENT Score Already Outdated?
}

\author{
Ales Rozman ${ }^{\mathrm{a}}$ Tony S.K. Mok ${ }^{\mathrm{b}}$

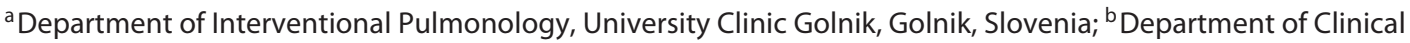 \\ Oncology, Chinese University of Hong Kong, Prince of Wales Hospital, Hong Kong, China
}

Malignant pleural effusion (MPE) is a complication of different metastatic cancers and therefore a common clinical challenge [1]. Median survival following its diagnosis is usually less than 12 months and is dependent on the type of underlying malignancy, performance status, treatment, and the characteristics of serum and pleural effusion markers [2-5]. Although lung and breast cancer are the most common causes of MPE, the prognosis for different patients with MPE varies widely, exposing the need to subcategorise MPE patients in order to tailor or individualise their treatment [6]. One of the most important questions is the estimated life expectancy of these patients, which influences palliative treatment decisions [7].

Several efforts have been made in the recent decades to predict the survival of patients with MPE [2, 8-10]. The most prominent among them was the development and initial validation of the LENT score on the basis of international cohorts of patients with MPE and different underlying malignancies [8]. The model stratifies patients into low-, moderate-, and high-risk groups on the basis of pleural fluid lactate dehydrogenase, Eastern Cooperative Oncology Group (ECOG) performance status, serum neutrophil-to-lymphocyte ratio, and tumour type. Lung cancer patients represented $27 \%$ of all included cases and were defined as the malignancy group with the worst prognosis. In a prior validation study, the LENT score appeared to predict overall survival (OS) significantly better than all other parameters, including ECOG performance status.

However, the LENT score has ignored the fact that non-small cell lung cancer is not homogeneous. Even more diversity brought the identification of oncogenic drivers such as EGFR, ALK, and ROS1, as well as the introduction of targeted therapies, which have had a significant impact on survival in recent years [11]. And yet, the LENT score has not addressed these important developments in management of advanced non-small cell lung cancer.

In the present issue of Respiration, Abisheganaden et al. [12] reports the application of the LENT score in a selected population of patients with MPE secondary to lung adenocarcinoma in Singapore. The key finding is that the LENT score considerably underestimated the prognosis for the selected patients with MPE and therefore needed modification in order to be applicable. The highest risk score of "2" that was attributed to lung cancer in the LENT score had to be substituted with a risk score of "0"

\section{KARGER}

(c) 2018 S. Karger AG, Basel

E-Mail karger@karger.com

www.karger.com/res
Dr. Ales Rozman

University Clinic Golnik

Golnik 36

SI-4202 Golnik (Slovenia)

E-Mail ales.rozman@klinika-golnik.si 
in the present study of adenocarcinoma patients in order to match the predicted prognosis. The question is what causes such a difference?

Histologic cell types are prognostic in patients with MPE secondary to lung cancer. In the recent study by Lee et al. [9], where serum and MPE neutrophil-to-lymphocyte ratios were evaluated as prognostic factors, a nonadenocarcinomatous histology was recognised as an independent predictor of shorter OS, although EGFR mutations were not defined and targeted therapy was not used. Similar results were obtained in other studies [10]. However, it is also known that lung adenocarcinoma with MPE is associated with a higher incidence of EGFR mutations than adenocarcinoma in the surgical stage [13]. Furthermore, the OS of patients with MPE due to lung adenocarcinoma was longer if they were treated with tyrosine kinase inhibitors (TKIs), which is best explained by the presence of EGFR mutations [14].

A higher prevalence of EGFR mutations is the other reason for Abisheganaden's study to be different from the LENT cohort trial. The prevalence of EGFR mutations in Abisheganaden's population was $55.7 \%$, and all patients with EGFR mutations also received TKI treatment [12]. The population of patients from which the LENT score was derived consisted of a UK, Dutch, and Australian cohort, where the prevalence of EGFR mutations was estimated between 12 and 15\% [15].

Although Abisheganaden et al. [12] modified the risk score for adenocarcinoma in the " $\mathrm{T}$ " domain of the LENT score to better match the prognosis for the group as a whole, it is fairly obvious that the population consists of two distinct prognostic groups: those with EGFR mutations treated with TKIs and those without EGFR mutations treated with chemotherapy. Keeping all patients together better serves to prolong the life of the LENT score, but it is a poor service to the accuracy of prognosis for a particular individual if crucial data have been excluded.

The LENT scoring system was created as a robust prognostic score in order to aid in decision-making regarding treatment of the diverse populations of patients with MPE [8]. However, the rapid development of new therapies and further phenotyping of MPE in the recent years have created new prognostic groups among patients with MPE due to lung cancer, let alone other cancer types. Targeted and immunotherapeutic treatments will further diversify prognosis in the future. The question is whether further modifications to the LENT score can keep it alive or whether it will soon die a death.

\section{References}

1 Desai NR, Lee HJ: Diagnosis and management of malignant pleural effusions: state of the art in 2017. J Thorac Dis 2017;9(suppl 10):S1111-S1122.

2 Zamboni MM, da Silva CT Jr, Baretta R, et al: Important prognostic factors for survival in patients with malignant pleural effusion. BMC Pulm Med 2015;15:29.

3 Abrao FC, Peixoto RD, de Abreu IR, et al: Prognostic factors in patients with malignant pleural effusion: is it possible to predict mortality in patients with good performance status? J Surg Oncol 2016;113:570-574.

4 Anevlavis S, Kouliatsis G, Sotiriou I, et al: Prognostic factors in patients presenting with pleural effusion revealing malignancy. Respiration 2014;87:311-316.

5 Yoon DW, Cho JH, Choi YS, et al: Predictors of survival in patients who underwent videoassisted thoracic surgery talc pleurodesis for malignant pleural effusion. Thorac Cancer 2016;7:393-398.
6 Lui MM, Fitzgerald DB, Lee YC: Phenotyping malignant pleural effusions. Curr Opin Pulm Med 2016;22:350-355.

7 Roberts ME, Neville E, Berrisford RG, et al: Management of a malignant pleural effusion: British Thoracic Society Pleural Disease Guideline 2010. Thorax 2010;65(suppl 2): ii32-ii 40.

8 Clive AO, Kahan BC, Hooper CE, et al: Predicting survival in malignant pleural effusion: development and validation of the LENT prognostic score. Thorax 2014;69:1098-1104.

9 Lee YS, Nam HS, Lim JH, et al: Prognostic impact of a new score using neutrophil-to-lymphocyte ratios in the serum and malignant pleural effusion in lung cancer patients. BMC Cancer 2017;17:557.

10 Kasapoglu US, Arınç S, Gungor S, et al: Prognostic factors affecting survival in non-small cell lung carcinoma patients with malignant pleural effusions. Clin Respir J 2016;10:791799.
11 Clark JW, Longo DL: Recent progress in systemic treatment for lung cancer. Curr Opin Pulm Med 2018;24:355-366.

12 Abisheganaden J, Verma A, Dagaonkar RS, et al: An observational study evaluating the performance of LENT score in the selected population of malignant pleural effusion from lung adenocarcinoma in Singapore. Respiration DOI: $10.1159 / 000489315$.

13 Wu SG, Gow CH, Yu CJ, et al: Frequent epidermal growth factor receptor gene mutations in malignant pleural effusion of lung adenocarcinoma. Eur Respir J 2008;32:924-930.

14 Wu SG, Yu CJ, Tsai MF, et al: Survival of lung adenocarcinoma patients with malignant pleural effusion. Eur Respir J 2013;41:14091418.

15 Midha A, Dearden S, McCormack R: EGFR mutation incidence in non-small-cell lung cancer of adenocarcinoma histology: a systematic review and global map by ethnicity (mutMapII). Am J Cancer Res 2015;5:2892-2911. 